los dibujos animados, estimo que estas películas con sus lauchitas intrusas, sus cuervos solapados y sus enloquecidos pájaros carpinteros, son mucho más aptas para los mayores que para los niños. El antropomorfismo de ellas es excesivo: los animalitos proceden y se mueven como verdaderos seres humanos. En cambio, en el relato, el bichito conserva más su naturaleza, sin desmedro de lo humano que el niño tanto gusta encontrar en él.

No les traigo muchas novedades con mis palabras. Sólo he repetido viejos nombres de autores que todos ustedes conocen: Andersen, Perrault, Grimm. Podré añadirles algo más reciente de Lewis Carroll, el autor de "Alicia en el País de las Maravillas", y el de Selma Lagerloff; podré recordar al italianito narigón que se llama Pinocho, pero sobre todo señalaré los tesores que en todos los folklores del mundo mantienen latentes sus mejores posibilidades, y recordaré, para terminar, que el mejor cuento es el que, utilizando con habilidad todos esos materiales, construyan ustedes mismas, posponiendo toda ambición literaria -que puede ser el peor enemigo- al logro de una sencillez apasionada que llegue a los pequeños. Y para eso, no me cansaré de repetir que la clave del secreto reside en el amor: amor al niño, no sólo en sus posibilidades y latencias, sino en su actualidad que es para él, como para cada una de nosotras, su mayor, y casi diría, su único tesoro. Guíadas por ese amor les será permitido penetrar -llevando de la mano a una criatura- al mágico país del árbol que canta, el agua que llora y el pájaro que habla...

\title{
Alfonso Echeverría
}

\section{DILEMA ENTRE LA LIBERTAD Y LA MEDIOCRIDAD EN LA LITERATURA CHILENA ACTUAL}

Muchas son las ideas que acuden a la mente en un encuentro como éste, organizado con visión y amplitud por la Universiclad de Concepción. El escritor mantiene un diálogo constante consigo mismo. A través de sus obras, lo mantiene también con sus lectores ocultos. Pero pocas veces le es dado el privilegio de dialogar, como ahora, con sus compañeros de oficio.

Acaso nuestro aporte sería mayor si cada uno de nosotros intentara expresar la substancia misma que anima su búsqueda, prescindiendo de toda divergencia de opinión. Pero sabemos que no basta hablar y escuchar, ni compartir un cierto espacio cubierto. Si hẹmos dę comunicarnos en el 
espacio psicológico, debemos hallar primero un lenguaje común, sentar un terreno de principios en el cual encontrarnos. Son tantas las limitaciones doctrinarias que los mismos escritores se han impuesto, y están estos prejuicios tan difundidos en Chile, que me tomaré la libertad de asumir una posición polémica, denunciando actitudes que considero fundamentalmente erradas. Si mis palabras suscitan un debate, tal vez pueda éste despejar conceptos y abrir los ánimos a un intercambio más fecundo.

"El escritor debe estar comprometido con su tiempo. Su obra debe tener trascendencia social. Debe esmerarse en describir lo autóctono. Debe ceñirse a las normas del género".

Estas voces las oímos con tanta frecuencia en Chile, que adquieren el tono irrefutable de la autoridad. Tres son las servidumbres que propician los partidarios del compromiso:

- Servidumbre al medio.

- Servidumbre a la doctrina.

- Servidumbre al género.

Examinemos primero la servidumbre al medio. No hay duda de que asistimos en Chile a un resurgimiento del criollismo. Se nos presenta despojado de la fatigosa insistencia en el "color local", y dirigido a descubrir las raices mismas de nuestra nacionalidad. El afán de los nuevos criollistas no es ya la descripción del adorno folklórico. Es un esfuerzo serio por hallar lo autóctono. $\mathbf{Y}$ antes de señalar lo que constituye, a mi juicio, su falacia fundamental y deplorable, quiero conceder pleno mérito a los puntos positivos de su planteamiento.

"El progreso exige a los hombres y a los continentes que abandonen su extrañeza", dice amargamente Romain Gary en su gran novela sobre los elefantes. Pues bien, esa extrañeza queremos conservarla. Queremos cultivar, queremos defender nuestra singularidad. Es lo más auténtico, es lo más profundo que poseemos. Pero no creemos que ella esté confinada a los límites estrechos de dialectos y costumbres. Tiene caracteres que rebasan esos límites. Frente a la soledad del habitante de América, frente a la magnitud de su residencia terrestre, el costumbrismo resulta chato y perisférico.

Es error tremendo de los criollistas creer que la nacionalidad ya está formada. Describen con fruición esa cáscara inerte de lo peculiar, le atribuyen valores definitivos y absolutos. Prescinden de aquello que está en germen, lo inédito y latente que jamás podrá exp̧resarse en fóșiles modismos. 
Me parece advertir en el criollista un desarraigo fundamental y paradógico. Sólo ve en su tierra lo que muy adentro en su espíritu califica de extravagante. Así, su actitud viene siendo un exotismo invertido. Si el turista de la literatura sale a vagar por tierras extrañas persiguiendo lo exótico - proceder censurable por lo frívolo- el criollista se queda en casa para servir de guía y exponer lo "típico" de su ambiente. Es un turista al revés. Un extranjerizante de lo nacional. Es el jardín zoológico desde el interior. La jaula vista por dentro. En el sentido vulgar y etimológico de la palabra, su visión del mundo es excéntrica. Está fuera del único centro que puede el hombre legitimamente reconocer que es su propia alma.

Superfluo decir que no es la extravagancia lo que nos interesa. Es aque110 que por ser auténtico no puede ser exótico en parte alguna del mundo. Aquello que en virtud de su singularidad, es, por eso mismo, universal. $\mathbf{Y}$ lo singular no está en el medio. Está exclusivamente en el hombre, en el fenómeno inverosimil que su existir presenta.

Paso en seguida a referirme al escritor militante, al que asume un compromiso con cierta posición doctrinaria y pone su obra al servicio de una causa. Tal actitud parece nutrirse en la premisa de que la función del escritor es de orden civico, es inducir a sus lectores a que enmienden entuertos de carácter público. A esto lo llaman "trascendencia social".

Yo diria que en la servidumbre doctrinaria hay, en esencia, una claudicación del destino trascendente del escritor. No me parece que sea misión suya remediar enfermedades sociales. Esta labor profiláctica, muy valiosa y necesaria, la desempeñan mejor los hombres abnegados que están al servicio de la comunidad. La función del escritor es más universal, más subjetiva y más vasta. Capturar en el tiempo, en la incierta realidad que lo circunda, los fragmentos dispersos de su propia alma, es para él tarea más urgente que proponer reformas y por cierto más urgente que divertir, como quisieran algunos críticos. Su exploración es demasiado oscura para hacer en ella de pedagogo, demasiado singular para hacer en ella de político, demasiado seria para hacer de cortesano. Cuando el escritor indaga en el misterio de su vocación no hay linterna doctrinaria que pueda alumbrarle el camino. Ni brújula capaz de substituir su propia angustia insobornable.

Reconozco las ventajas de una filiación política. Doctrinas anacrónicas como el marxismo, productos caducos del siglo XIX, ofrecen al autor que les rinde tributo un servicio de difusión muy eficaz. Desgraciadamente, no es un servicio gratuito. El precio es la posesión más valiosa dẹl escritor 
intransigente: su libertad. Sostengo que los escritores profilácticos son periodistas o políticos que han errado camino. Su lugar está en las asambleas, las campañas y las tribunas. No está en la soledad del oficio literario.

Pertenecemos a una edad que ha visto desplomarse los valores. El escritor no se salva del sentimiento de desamparo que envuelve a los hombres. Por cl contrario, lo experimenta aún más fuertemente. Y no siempre capaz de soportarlo, busca refugio en movimientos, ideologias y grupos. Esto tiene relación con la tercera servidumbre. Nuestro siglo asiste al colapso de la rigidez. Ya no existen fronteras entre las disciplinas. En beneficio de una mayor soltura de expresión, las reglas del juego han sido rotas. Ello es cierto en pintura, es cierto en el teatro, en la música, en la ciencia. Es cierto también en la creación literaria. Esta gran crisis bienhechora nos permite escribir sin tener que ajustarnos a normas infranqueables. Así como el físico penetra en el reino de la química, y las ciencias tienden a integrarse, asi también la poesia se compenetra con la prosa, la ficción se mezcla con la realidad. Nuestra época admite la libertad, pero no tolera el artificio. Todo virtuosismo deliberado cae fuera de la época. En contraste con la sinceridad que ella exige, resulta casi una blasfemia.

Ignorando este fenómeno, muchos son en Chile los que endiosan recetas en la forma. Así, los autores de ficción, sea ella cuento o novela, han consagrado al dios Agilidad. Califican de disgresión superflua aquello que no es movimiento muscular. Y llaman a su búsqueda un "afán de ascetismo, de apartar del acontecer dramático todo lo que pueda serle accesorio". Este énfasis fanático en la acción es causa de que algunas de sus novelas nos recuerden el cine. $\mathrm{Y}$ no un cine con dimensión y sonoridad. Por el contrario. Tal novelística, al igual que el cine mudo, oculta su falta de recursos con carreras y gestos desenfrenados. Olvida que la ficción puede vibrar sin desplazarse. Puede tener la calma de las aguas profundas. No es indispensable que corra sobrc un cauce seco.

Examinemos ahora los rasgos comunes de las tres servidumbres. Todas ellas parecen emanar de una fe considerable en lo deliberado. El autor se propone un objetivo: revelar lo autóctono, demostrar una tesis, fabricar un poema, un cuento, una novela. Trazado el plan, lo sigue y lo cumple. Su espontaneidad creadora se ve restringida a los límites estrechos que le impone su objetivo. Nace, por asi decir, momificada. No puede ni pretende traspasar fronteras.

Esa confianza excesiva en lo racional mutila y atrofia la potencialidad del escritor. Es responsable, a mi juicio, del carácter senil que tales produccio- 
nes presentan. La Edad de la Razón murió para siempre con el siglo pasado. Revivirla resulta anacrónico. Hay en ello una falta de humildad, una falta de asombro. Si perdemos la facultad de maravilla, perdemos también la facultad creadora. Y no podemos prever, no podemos subordinar nuestro asombro. Debemos saludarlo reverentemente cada vez que aparece. Es la única fidelidad que nos exige el arte.

Yo propongo a los que aún conservan la fe en sí mismos que no nos cobijemos en la luz artificial de una escuela, de una doctrina, de un regionalismo. Les propongo que salgamos a la intemperie, a la vasta soledad de nuestra tierra, y tengamos el valor de articular nuestra propia voz insubstituible. Será una voz más perdida, más oscura, más vacilante. Pero será la nuestra.

\section{JORGE EDWARDS}

\section{EXPERIENCIA PERSONAL Y CREACION LITERARIA}

Claudio Giaconi, en su trabajo leido en estas jornadas, ha descrito algunos de los caracteres de nuestra generación; ha bosquejado una imagen de lo que éramos en el año 1950, cuando comenzábamos a escribir, y ha señalado nuestro espíritu inconformista, nuestra desconfianza, nuestro escepticismo radical, que incluso nos hacía sospechoso el escepticismo demasiado explotado literariamente de nuestros predecesores. A la vez, ha intentado definir el cambio que hemos experimentado desde entonces. Para ello ha tomado pie en su experiencia literaria personal, necesariamente única. Sin embargo, su análisis me hizo sentir, en forma verdaderamente punzante, que algo paralelo, común, sucedió en todos nosotros. Me hizo pensar que inevitablemente formamos una "generación", cosa que antes me resultó difícil concebir, ya que uno de los caracteres más esenciales de nuestra actitud era, y en parte sigue siéndolo, el aislamiento, la intima soledad. Pero esa soledad, ahora lo veo, nos hermanaba extrañamente.

Muchas veces he iniciado una novela sobre aquella época nuestra, en un esfuerzo por definirla y definirme, pero siempre, por algún motivo que no logro comprender cabalmente, he debido suspenderla. Quizás no esté libre aún, por completo, de aquel espiritu insatisfecho y burlón, y ello paralice mi trabajo. O quizás una vez que la escriba logre dejar dicho espiritu atrás, o mejor, incorporarlo, ya superado, a la suma de la experiencia personal. 